\title{
Design and Analysis of Meander Microstrip Antenna at Wireless Band
}

\author{
Ogherohwo, E. P \\ Department of Physics, \\ University of Jos,P.M.B 2084, \\ Jos Plateau State, Nigeria
}

\author{
Mado, S.D. \\ Department of Physics, \\ University of Jos,P.M.B 2084, \\ Jos Plateau State, Nigeria
}

\author{
Eggah, M.Y \\ Department of Physics, \\ University of Jos,P.M.B 2084, \\ Jos Plateau State, Nigeria
}

\begin{abstract}
Meander line antenna (MLA) is an electrically small antenna which poses several performance related issues such as narrow bandwidth, high VSWR, low gain and high cross polarization levels. This paper describe the design ,simulation and development of meander line microstrip antenna at wireless band, the antenna was modeled using microstrip lines and $\mathrm{S}$ parameter for the antenna was obtained. The properties of the antenna such as bandwidth, beamwidth, gain, directivity, return loss and polarization were obtained.
\end{abstract}

\section{Keywords:}

Meander line, wireless band and substrate.

\section{INTRODUCTION}

Recently, due to rapid changes in wireless communication technologies,there is rapid increase in data rate and at the same time reduction in antenna size and weight is require.There are varieties of techniques to reduce the size of microstrip antennas:the use of high permittivity substrates[1], shorting pins [2] and meander line .Inserting suitable slots in radiating patch is also a common technique in reducing the dimension of patch antenna.The slots introduce parasitic capacitances which tend to reduce the resonant frequency of the antenna .for wireless communication applications such as modem, radio Frequency identification tags.Bluetooth handset, Mobilephone, Meander line antenna is convincing solution [3].Meander line antenna is a type of the microstrip antennas. The meander line antenna was proposed by Rasheed and Tai for reducing the resonant length[4].Meandering the patch increases the patch over which the surface current flows and that eventually results in lowering of the resonant frequency than the straight wire antenna of same dimensions.

This paper present the design, modeling and performance analysis of meander microstrip antenna in the wireless band, this provide a good initial geometrical configuration of the antenna.

\section{2.0 Meander Antenna Theory}

The electrical small antenna defines as the largest dimension of the antenna is no more than the one-tenth of a wavelength [5].Meander antenna is electrically small antenna. The design of meander line antenna is a set of horizontal and vertical lines. Combination of horizontal and vertical lines forms turns. Number of turns increases efficiency increases.in case of meander line if meander spacing is increase, resonant frequency decreases. At the same meander separation increases resonant frequency decreases[6].A meander antenna is an extension of the basic folded antenna and frequencies much lower than resonances of a single element antenna of the equal length. Radiation efficiency of meander line antenna is good as compare to conventional half and quarter wavelength antennas. Antenna size reduction factor $\alpha$ depends primarily on the number of meander elements per wavelength and spacing of the element widths of the rectangular loops.

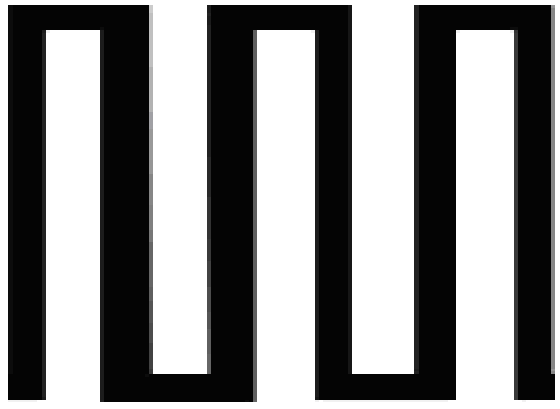

The meander line element consists of vertical and horizontal line so it formed a series of sets of right angle bends. The polarization of antenna depends on radiations from the bend, the spacing between two bends is very vital, where if the bends are too close to each other, then cross coupling will be more, which affects the polarization purity of the resultant radiation pattern. In other case the spacing is limited due to the available array grid space and also the polarization of the radiated field will vary with the spacing between the bends, and the spacing between the microstrip lines [1],the width of etch (line etch on PCB) used here is $0.65 \mathrm{~mm}$.

Planar meander line antenna with added quarter parasitic element at both side of the meander can produce double radiation pattern at frequencies much lower than resonances of a single element antenna of equal length [5]. A planar line monopole antenna element is the most suitable choice for MIMO antenna system.

\subsection{Meander Antenna Design}

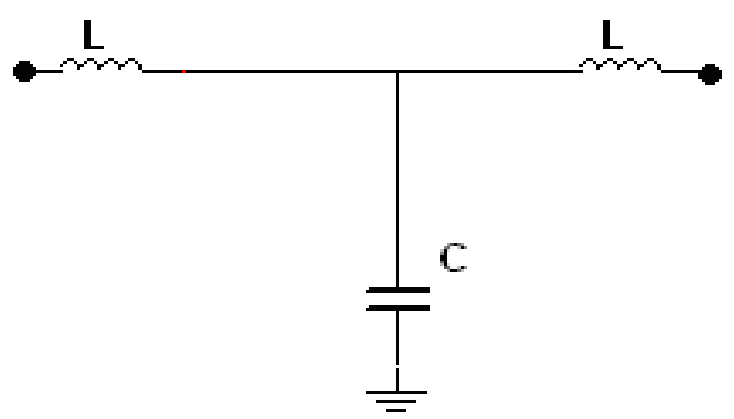

The meander line antenna acts as a resonant LC circuit. The vertical elements act as the inductor, horizontal elements act as capacitor. The horizontal line lies in the short length of the PCB while the vertical lines are placed along the long length of the PCB.The meander line configuration of the monopole allows reducing the occupied space of the antenna element to less than $0.1 \lambda_{o}$ in each dimension

The lumped inductance and capacitance are calculated given by [3] as follows: 
Lumped inductance

$$
L_{A}=\frac{L l}{2}
$$

Lumped capacitance $C_{B}=C l$

Where $\mathrm{L}$ is the inductance per unit length

$\mathrm{C}$ is capacitance per unit length and 1 is length of the line segment [10]

Total length of antenna is given as $N \times S=\frac{\lambda}{10}$

$\mathrm{N}=$ number of turns, $\mathrm{S}=$ spacing between two meander lines.

The characteristic impedance of each meander section given as :

$$
Z_{o}=276 \log \left(\frac{2 S}{d}\right), \mathrm{d}=\text { monopole wire diameter. }
$$

\subsection{Antenna Structure}

The meander line microstrip antenna iscreated using meander line and shaped ground as shown in Figure 1.on rectangular FR4 substrate, the schematic formed using MLINE, MLOC and MCURVE on Agilent software (ADS) and the layout simulated using momentum simulator.

Thickness of substrate $(\mathrm{h})=1.06$

Relative permittivity $\left(\mathcal{E}_{r}\right)=4.77$

Length of meander $=12.75 \mathrm{~mm}$

Width $=2.56 \mathrm{~mm}$

Spacing $=0.62 \mathrm{~mm}$

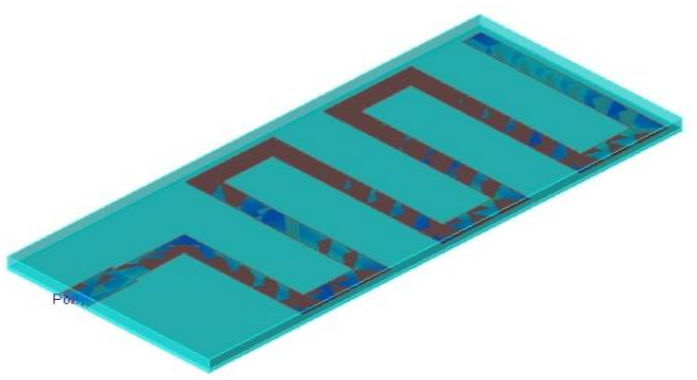

Figure 1: The Layout of the Propose Meander Microstrip Antenna

\section{RESULTS AND DISCUSSION}

The simulation of the parameters for the antenna was done using Agilent software (ADS2009) Advance design System,Figure 3-6 show the S parameter measurement for the rectangular meander microstrip antenna were presented, such parameters are the return loss for both input and output, the gain ,directivity, effective angle as well as the efficiency and the bandwidth. The resonant frequency obtained is $2.424 \mathrm{GHz}$ at a return loss of $-5.163 \mathrm{~dB}$ with impedance bandwidth of $15 \mathrm{~dB}$, directivity of $4.73 \mathrm{~dB}$, Gain of $4.10 \mathrm{~dB}$; power radiated is 7.33E-06 watts and effective angle of 4.22 steridian.
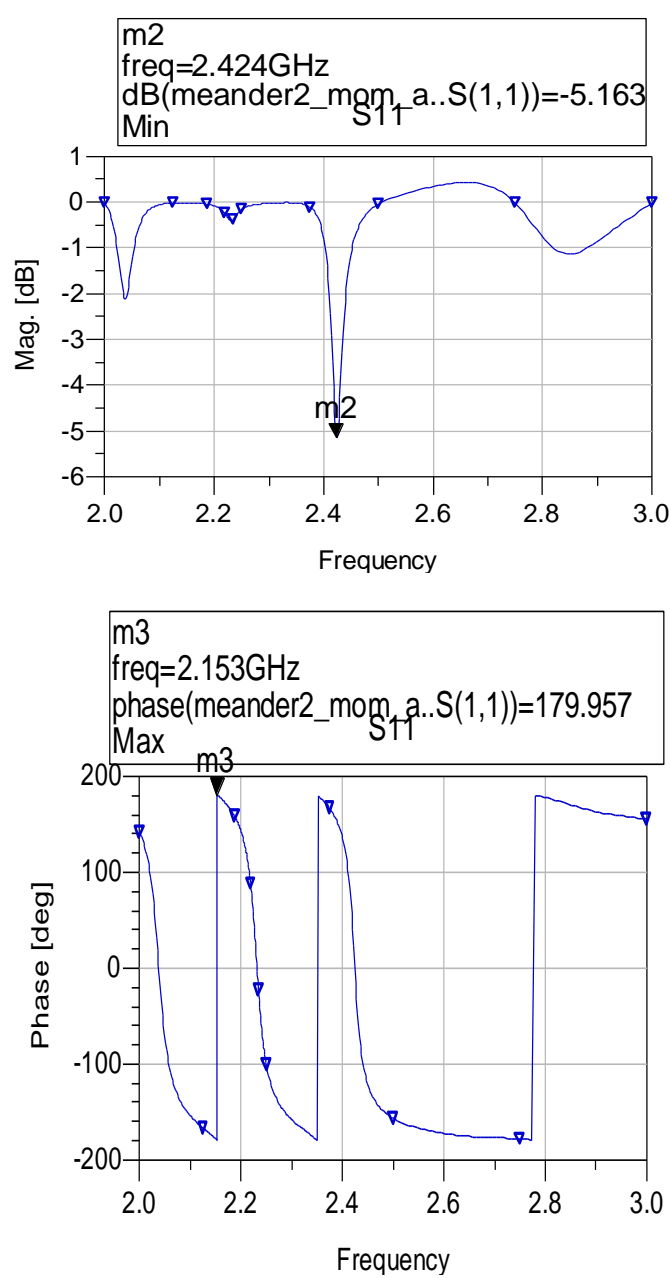

Figure 1:Output Return Loss and input return loss

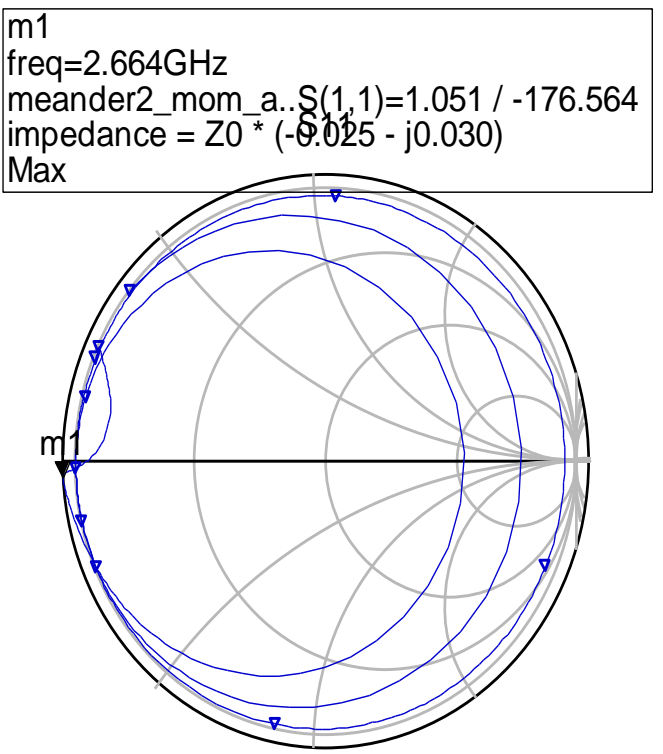

freq $(2.000 \mathrm{GHz}$ to $3.000 \mathrm{GHz})$

Figure 2: Simulated input impedance of Meander Microstrip patch 


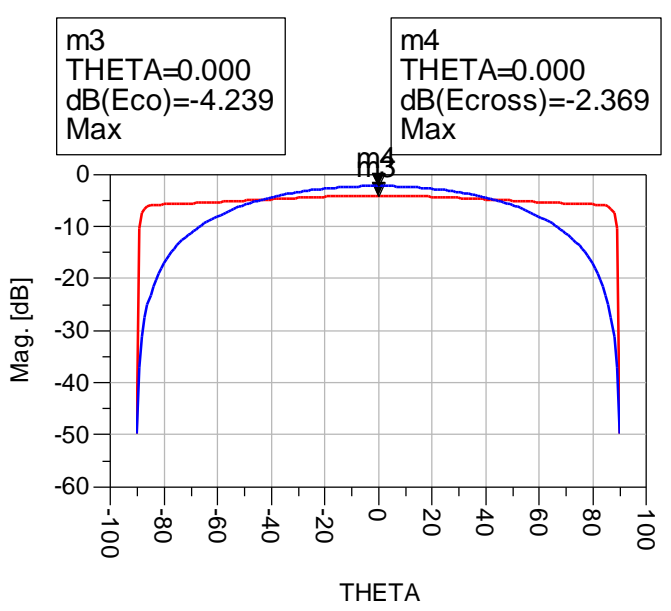

Figure 3:2D Simulated Cross Polarization

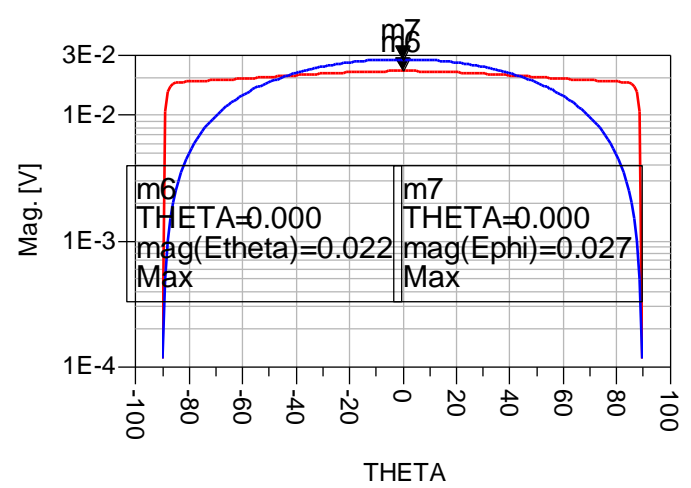

Figure 4:2D radiation pattern for the antenna

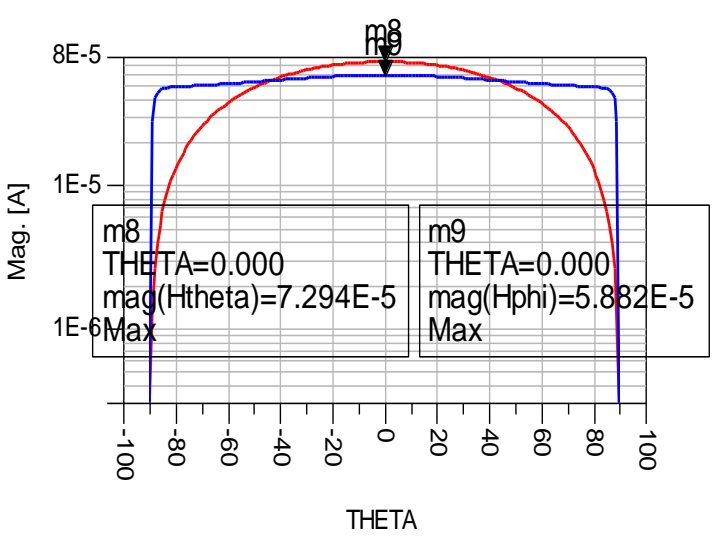

Figure 5:2D Magnetic Field Radiation pattern

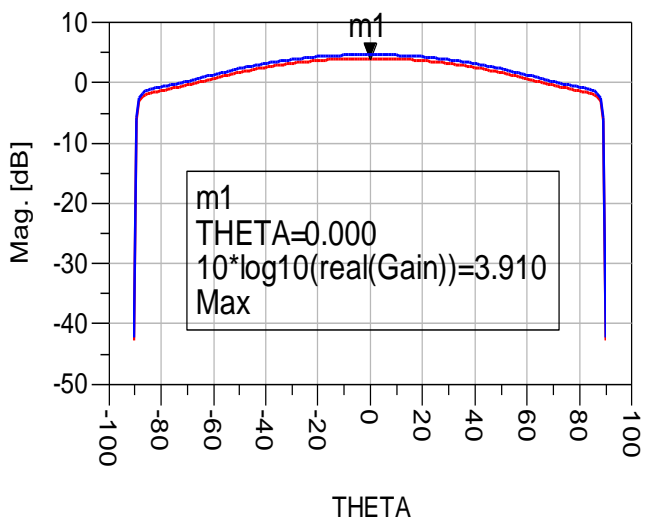

Figure 6: Maximum Gain of the Meander

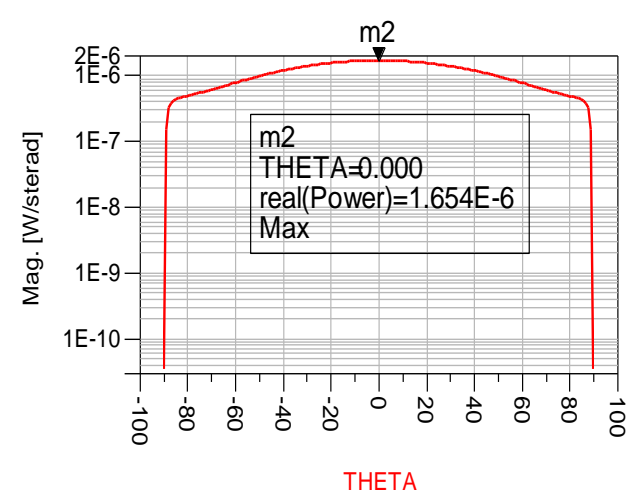

Figure 7:Radiated power in $\mathrm{dB}$

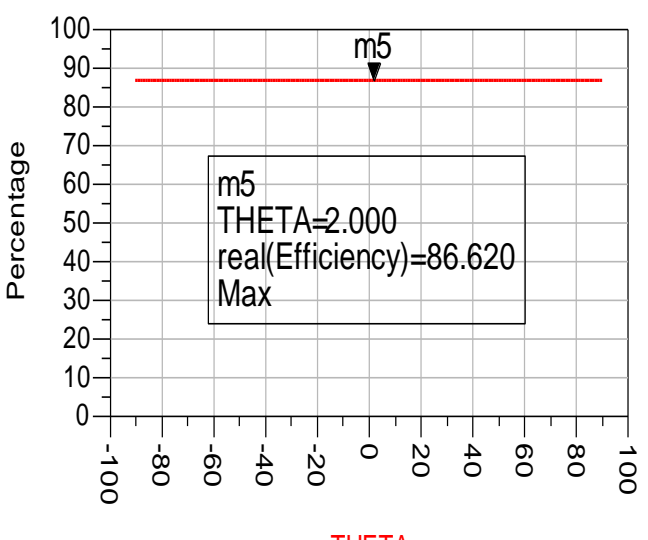

THETA

Figure 8: Efficiency

Table 2: Simulated Parameters for the Meander Line Microstrip

\begin{tabular}{|c|c|c|c|c|c|c|c|}
\hline $\begin{array}{l}\text { Resonant } \\
\text { Frequency }\end{array}$ & $\begin{array}{l}\text { Reflection } \\
\text { Coefficient }\end{array}$ & $\begin{array}{l}\text { Power } \\
\operatorname{rad}(s t)\end{array}$ & Eff. Angle & $\begin{array}{l}\text { Directivity } \\
\text { (dB) }\end{array}$ & $\begin{array}{l}\text { Gain } \\
\text { (dB) }\end{array}$ & $\mathbf{E}(\boldsymbol{\theta})$ degree & H(t)degree \\
\hline $2.424 \mathrm{GHz}$ & -5.163 & 7.3305E-06 & 4.2295 & 4.73 & 4.10 & $7.294 \mathrm{E}-5$ & $5.882 \mathrm{E}-5$ \\
\hline
\end{tabular}

\section{CONCLUSION}

The design and performance analysis of compact single meander microstrip Antenna at $2.0 \mathrm{GHz}-3.0 \mathrm{GHz}$ is presented. The resonant frequency of the antenna is $2.424 \mathrm{GHz}$, Gain is $4.73 \mathrm{~dB}$, Return loss, radiation patterns and power radiated were simulated using Advance Design System (ADS). From the whole band the simulated parameters was in agreement with the desired value of the design.In addition, the proposed antenna can be further design for wireless application. 


\section{REFERENCES}

[1] Ambhore .V.B and Dhande A.P "An Overview on Properties ,Parameter Consideration and Design of Meandering Antenna (IJSSAN,2012)

[2] Wong K.L, Planar antennas for wireless communications, New York,2003.

[3] Balanis C.A. Antenna Theory :Analysis and Design .New York:Willey .Second ed..1997.

[4] Rashed .J and Tai C.T,"A new class of resonant antennas"IEEETrans.Antennas Propagation Vol.39,pp 1428-1430,Sept.1991.
[5] Best S.R and Morrow J.D "Limitations of inductive Circuit model representations of meander line antennas",vol.1,pp852-855,IEEE Trans..Antennas and Propagation Society International Symposiuym,June 2003.

[6] WarnagirisT.J,andMinardoT.J,"Performance of a meandered line as an electrically small transmitting antennas "Antyenna and Propation ,IEEE Transaction on,vol.46no.12pp.1797-1801.Dec 1998. 